Supplement of Atmos. Chem. Phys., 14, 11697-11709, 2014

http://www.atmos-chem-phys.net/14/11697/2014/

doi:10.5194/acp-14-11697-2014-supplement

(C) Author(s) 2014. CC Attribution 3.0 License.

(c) (1)

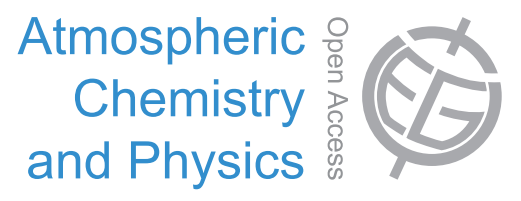

Supplement of

\title{
Biases in modeled surface snow BC mixing ratios in prescribed-aerosol climate model runs
}

\section{S. J. Doherty et al.}

Correspondence to: S. J. Doherty (sarahd@atmos.washington.edu) 
Supplement of Atmos. Chem. Phys., 14, 11697-11709, 2014

http://www.atmos-chem-phys.net/14/11697/2014/

doi:10.5194/acp-14-11697-2014-supplement

(C) Author(s) 2014. CC Attribution 3.0 License.

(c) (1)

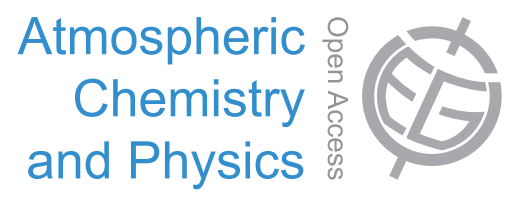

Supplement of

\section{Biases in modeled surface snow BC mixing ratios in prescribed-aerosol climate model runs}

\section{S. J. Doherty et al.}

Correspondence to: S. J. Doherty (sarahd@atmos.washington.edu) 
Figure S1. Three-month seasonal averages of the ratio $\left[M R_{B C}\right]_{\mathrm{d}}:\left[M R_{B C}\right]_{\mathrm{y}}$ for model gridboxes around Greenland for a) winter (DJF), b) spring (MAM) and c) summer (JJA), using CESMmet. These ratios indicate the effect on surface snow mixing ratios of having $\mathrm{BC}$ wet deposition fluxes and snowfall decoupled $\left(\left[M R_{B C}\right]_{\mathrm{d}}\right)$ vs. using a more physically consistent pairing of climatologically averaged $\mathrm{BC}$ wet deposition with 10 year average snowfall $\left(\left[M R_{B C}\right]_{\mathrm{y}}\right)$.

(a)

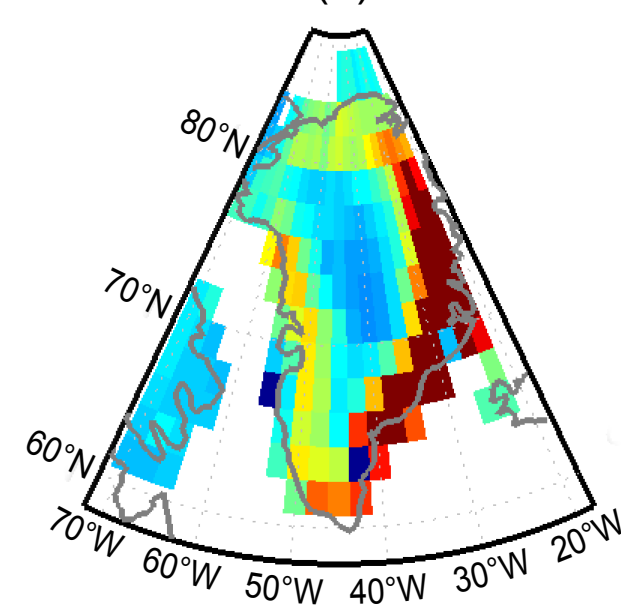

(b)

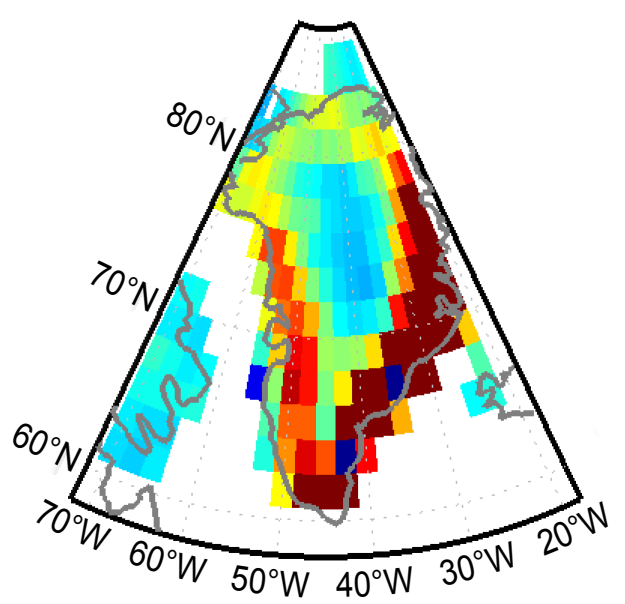

(c)

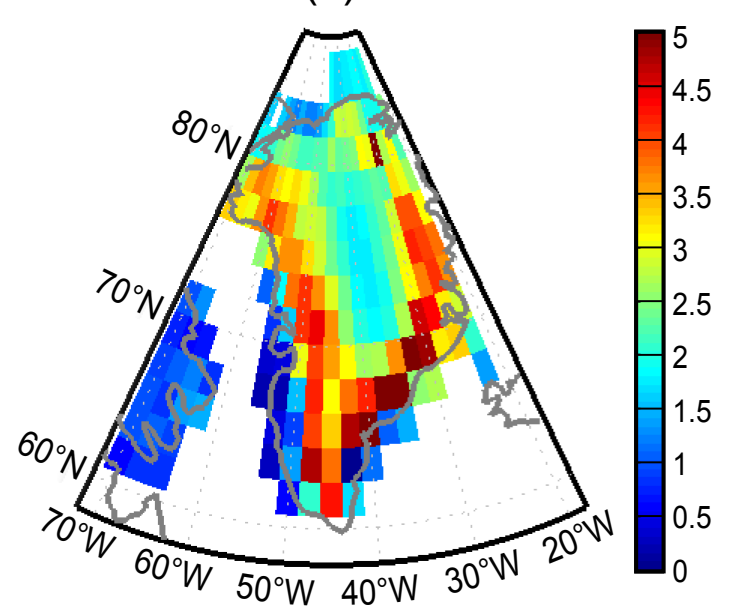


Figure S2. As in Figure S1, but for the Eurasian region in a) winter (DJF) and b)

11

12 spring (MAM).
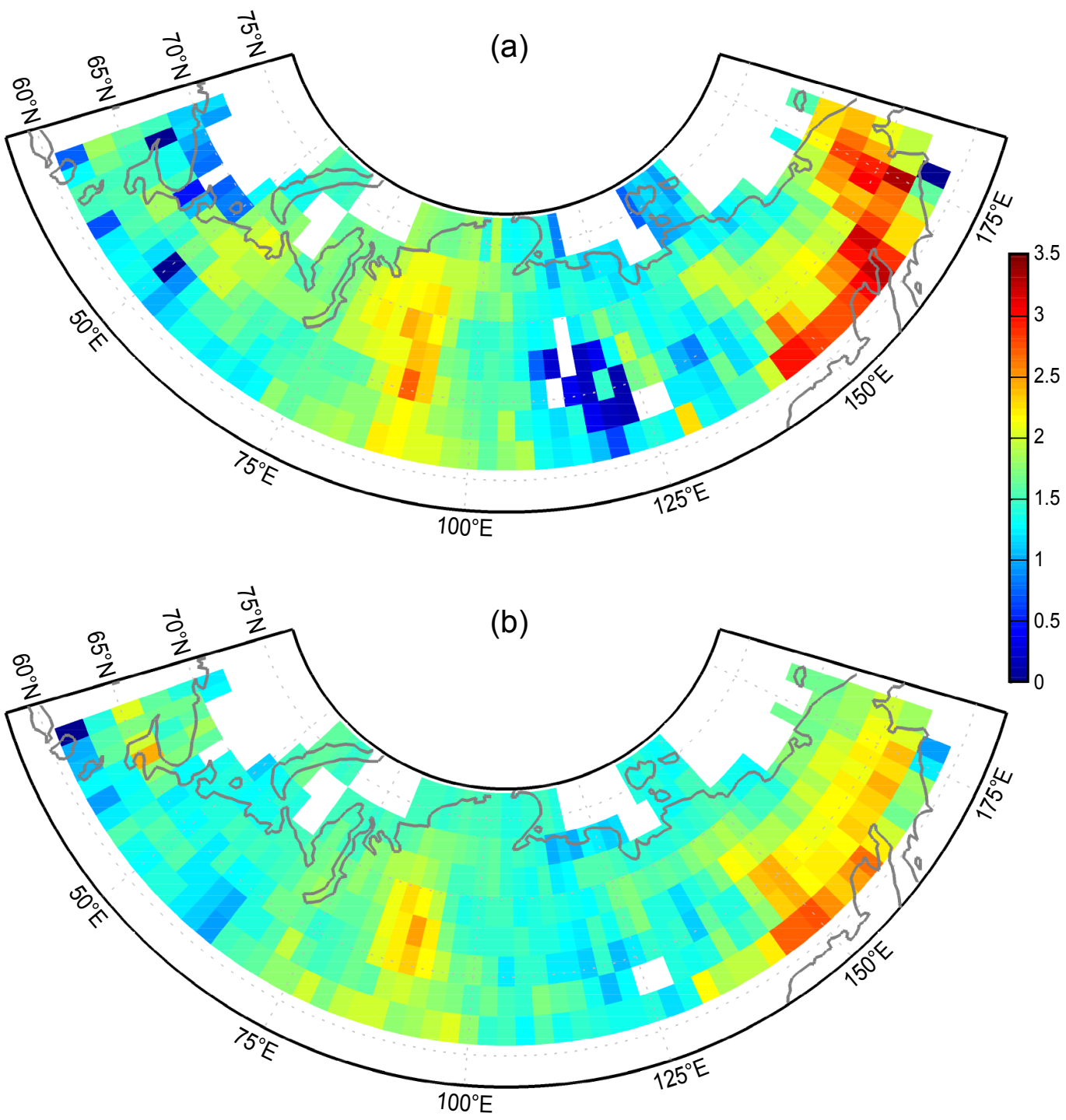

13 


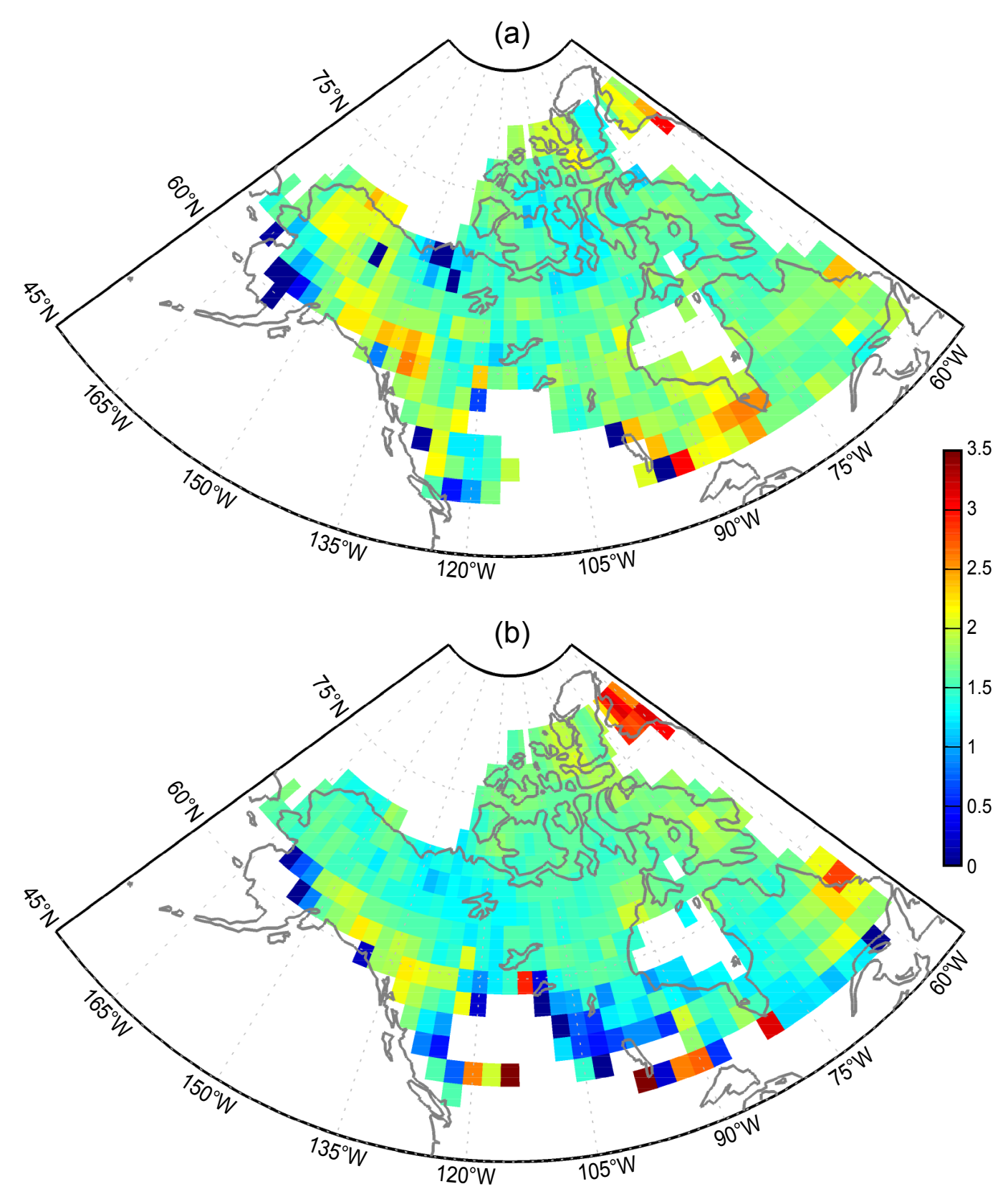


31 Figure S4. Relative frequency histograms of daily-average BC mass deposition fluxes (dry+wet) on days with snowfall, (top), snow water equivalent in snowfall (middle), and surface snow $\mathrm{BC}$ mixing ratios (bottom), for all gridboxes containing land surfaces in the Greenland region shown in Figure S1. Histograms are show for CESM runs where aerosol deposition fluxes were calculated prognostically, and for a set of CESM runs where aerosol deposition fluxes were prescribed. The prognostic-aerosol values are averages across 30 runs using year 2000 emissions, running CESM1.0/CAM5. The prescribed-aerosol values are averages across 20 runs of CESM1.0/CAM4 using prescribed aerosol depositions representative of year 2000, as described in the main text. Note that the peak of the relative frequency bar for the prognostic-aerosol runs' surface snow layer $\mathrm{BC}$ mixing ratio in the bin for $0-2 \mathrm{ng} \mathrm{g}^{-1}$ is off-scale; it is 1680 . The highest bin in each histogram includes contributions from higher values (e.g. BC deposition fluxes $>19 \mathrm{ng} \mathrm{m}^{-2}$ day $^{-1}$ in the top figure below).
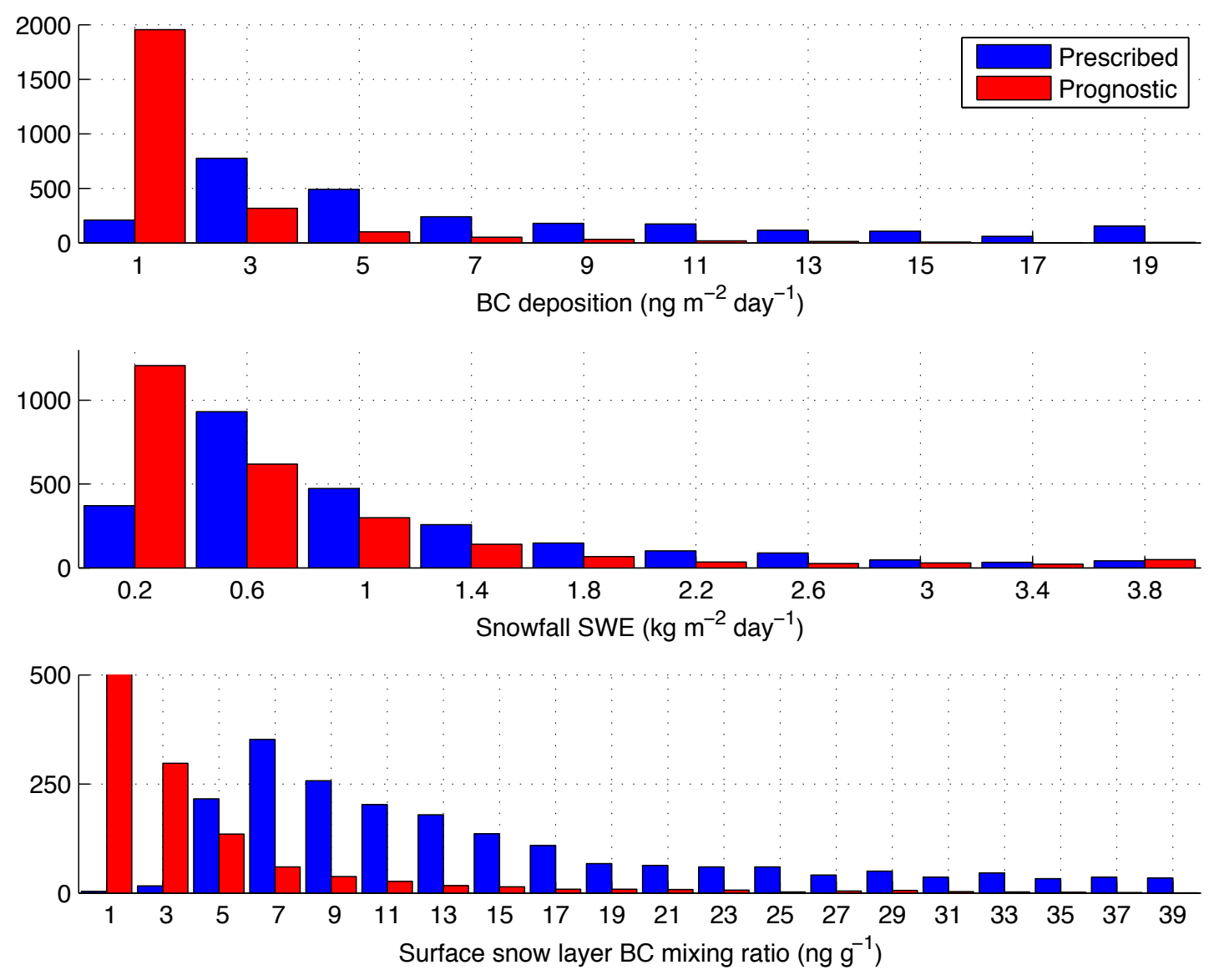
$48 \quad$ Figure S5. As in Figure S4, but for the Eurasian region, as shown in Figure S2.

49
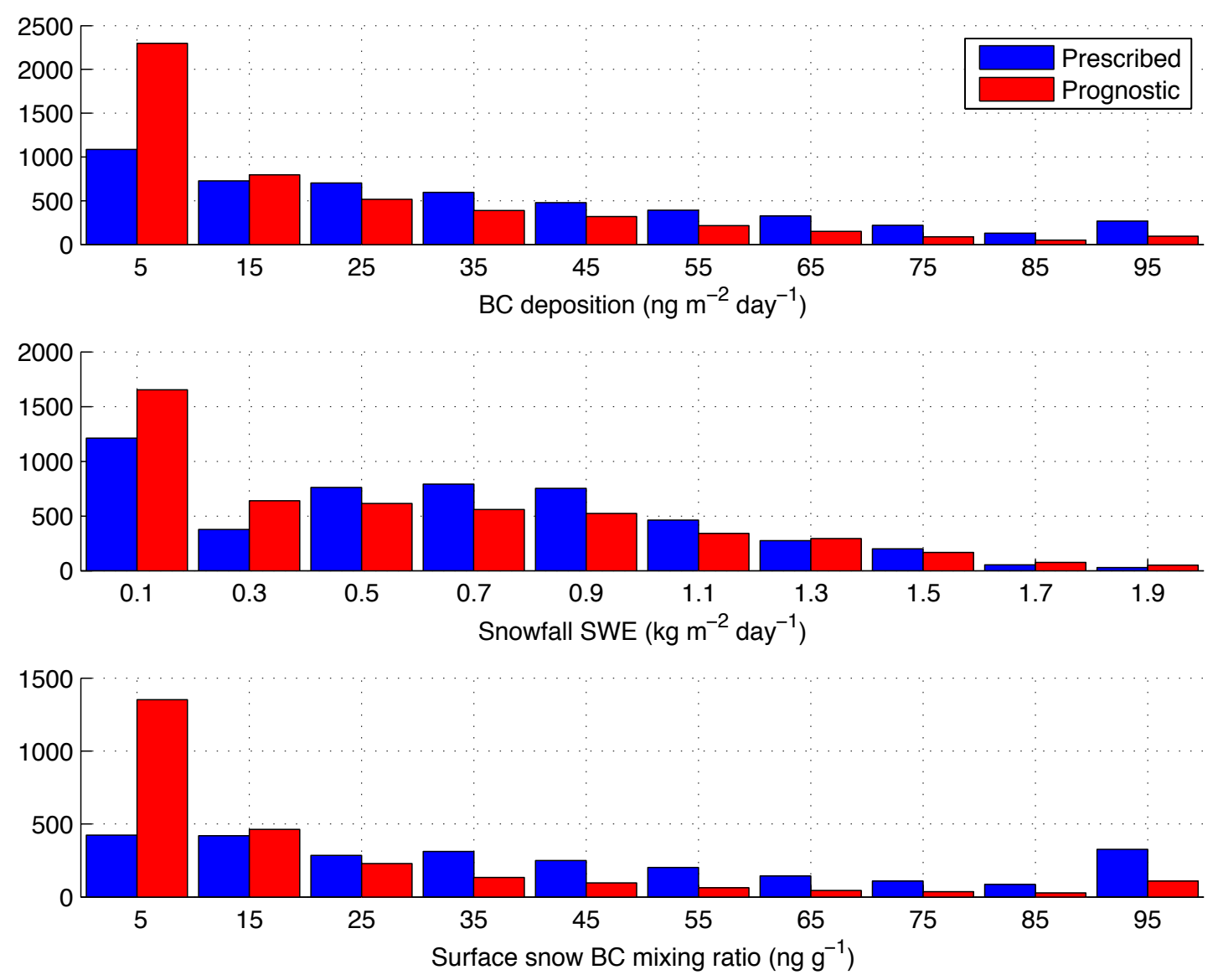

50

51 
52 Figure S6. As in Figure S4, but for the North American region, as shown in Figure S3.

54
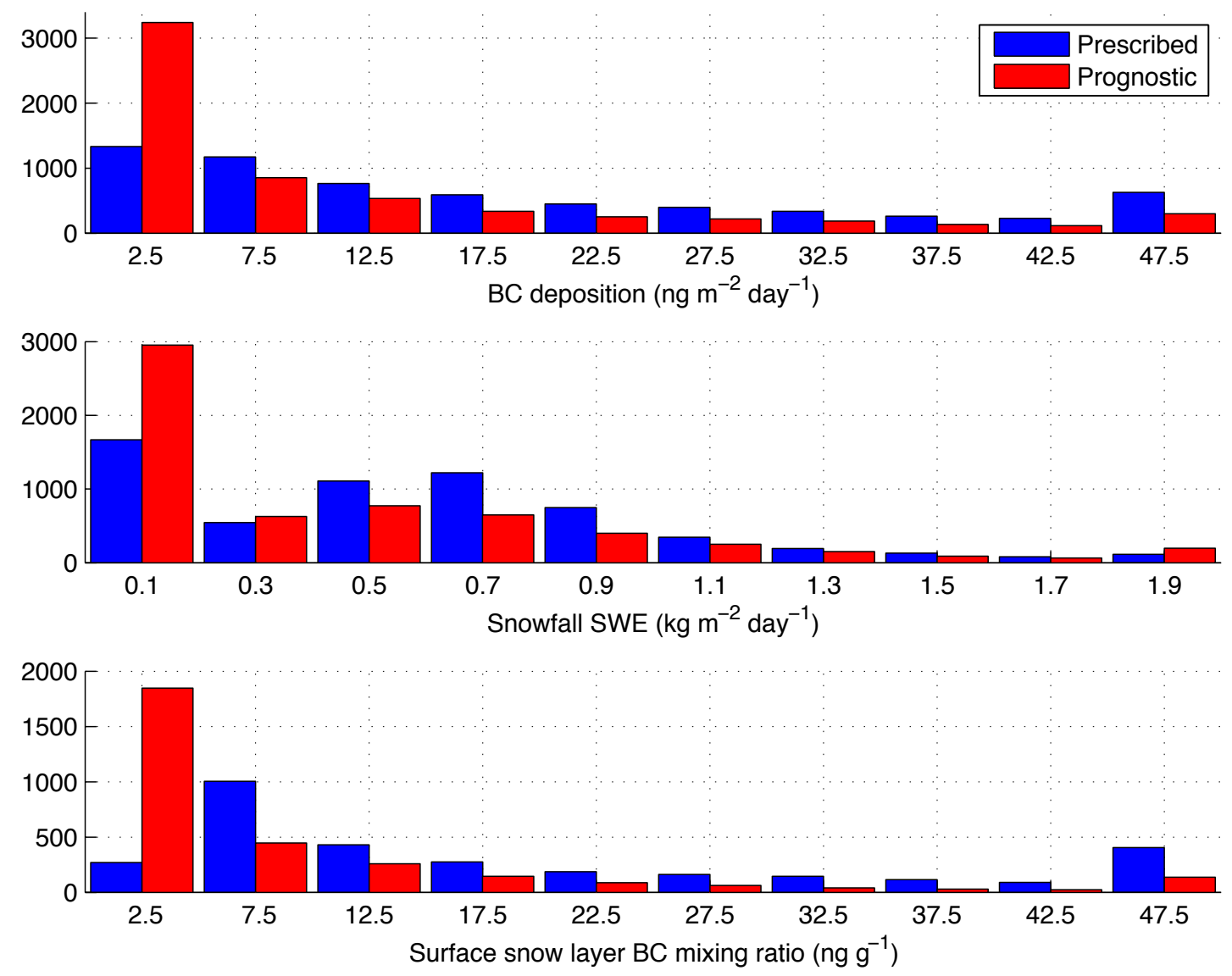